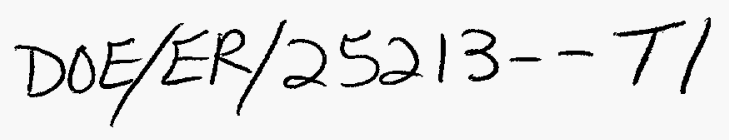

\title{
Final Report on Characterizing the Dynamics of Spatio-Temporal Data
}

\author{
Principal Investigator: Eric J. Kostelich \\ Co-Principal Investigator: H. Dieter Armbruster \\ DOE Award number DE-FG03-94ER25213 \\ Department of Mathematics \\ Arizona State University \\ Tempe, AZ 85287-1804
}

\section{Summary}

One principal goal of the grant was to model and analyze the dynamics of spatially extended chaotic systems. One of the principal tools used in the analysis was KLTOOL, a computer package developed by the principal investigators for Karhunen-Loève analysis. The package was used to analyze video data from a labouatory experiment, performed by Michael Gorman and collaborators at the University of Houston, on cellular flames. A wide variety of complex dynamics are observed depending on factors such as the mix of reactants and ambient pressure. At present, there is no satisfactory mathematical modil of the dynamics, but the Ph.D. research of José Palacios, who was supported by this grant, showed that in many cases the dynamics were relatively low dimensional, and he was able to characterize the behavior of the flames in terms of periodic saddle orbits. The K-L analysis was also used to analyze the apparent symmetries that govern the dynamical behavior of ch certain two-dimensional model of fluid flow; this work was completed by Nejib Smaoui, a graduate student and postdoc in the mathematics department in collaboration with D. Armbruster and others.

A second goal of the project was to analyze complex time series whose underlying dynamics máy be low dimensionally chaotic. Particular emphasis was placed on systems of possible relevance to energy production and distribution. The work with Stuart Daw and collaborators attempted to characterize low-dimensional aspects of the dynamics of a fluidized bed, in
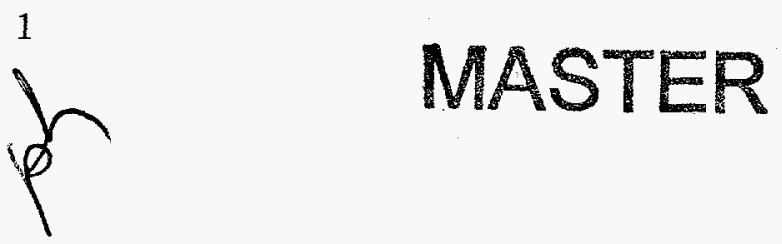


\section{DISCLAIMER}

This report was prepared as an account of work sponsored by an agency of the United States Government. Neither the United States Government nor any agency thereof, nor any of their errployees, makes any warranty, express or implied, or assumes any legal liability or responsibility for the accuracy, completeness, or usefulness of any information, itpparatus, product, or process disclosed, or represents that its use would not infringe privately owned rights. Reference herein to any specific commercial product, prixess, or service by trade name, trademark, manufacturer, or otherwise does not llecessarily constitute or imply its endorsement, recommendation, or favoring by the United States Government or any agency thereof. The views and opinions of authors expressed herein do not necessarily state or reflect those of the United Stites Government or any agency thereof. 


\section{DISCLAIMER}

Portions of this document may be illegible electronic image products. Images are produced from the best available original document. 
particular, a transition from periodic to irregular behavior. E. Kostelich worked with Efrain O'Neill, who is a graduate student in electrical engineering, and G. Heydt, a faculty member in the Department of Electrical Engineering at ASU, to characterize the dynamics of an electric arc furnace and to construct a power quality model that incorporates chaotic (as opposed to stochastic) forcing from the arc furnace. The model's output appears to mimic observed "real-world" measures of power quality much better than models that assume entirely stochastic behavior in arc furnaces. This work will appear in the IEEE Transactions on Power Quality.

Finally, E. Kostelich and collaborators worked on aspects of targeting in chaotic dynamical systems. This work showed that it is possible to switch a moderately high-dimensional chaotic process rapidly between prespecified periodic saddle orbits embedding within the attractor. Additional work extended previously-developed algorithms for the highly accurate computation of stable manifolds of periodic saddle orbits, which is essential to the successful application of targeting algorithms.

\section{Graduate students siupported by the grant}

- J. Palacios, Ph.D. in mathematics awarded May 1995.

- M. Mincheva; Mas jer's degree in mathematics awarded May 1997.

- I. Diaz-Rivera; Ph.D. in mathematics awarded May 1998. She is writing up her work fo: publication in Fall 1998.

- W. Qian, Ph.D. in mathematics awarded May 1997.

\section{Research papers resulting from the grant support}

1. E. O'Neill-Carrillo. G. T. Heydt, E. J. Kostelich, S. S. Venkata, and A. Sundaram, "Nonlinear deterministic modeling of highly varying loads," IEEE Trans. on Power Delivery, to appear.

2. E. J. Kostelich, I. Kan, C. Grebogi, E. Ott, and J. A. Yorke, "Unstable dimension variability: a source of nonhyperbolicity in chaotic systems," Physica D, 109 (1997), 81-90.

3. D. Armbruster and N. Smaoui, "Symmetry and Karhunen-Loève Analysis," SIAM J. of Sicientific Computing 18 (1997), 1526-1533.

4. E. Barreto, F. Casias, C. Grebogi, and E. J. Kostelich, "Control of Chaos: Impact Oscillators and Targeting," in IUTAM Symposium on 
Interaction between Dynamics and Control in Advanced Mechanical Systems, ed. by [1. H. van Campen. Dordrecht, The Netherlands: Kluwer Academic Publishers, 1997, pp. 17-26.

5. E. J. Kostelich, "The analysis of chaotic time series data," Systems \& Control Letters 31 (1997), 313-319.

6. S. Boccaletti, A. Farini, E. J. Kostelich and F. T. Arecchi, "Adaptive targeting of chaos," Phys. Rev. E 55 (1997), 4845-4848.

7. E. J. Kostelich and E. B. Barreto, "Targeting and control of chaos," in Control and Chaos, ed. by K. Judd, A. Mees, K. L. Teo and T. Vincent. Boston: 33irkhäuser, 1997, pp. 158-169.

8. A. Palacios, D. Armbruster, E. J. Kostelich, and E. Stone, "Analyzing the dynamics of cellular flames," Physica D 96 (1996), 132-161.

9. D. Armbruster, B. Nicolaenko, N. Smaoui, and P. Chossat, "Symmetries and Dynamic; for 2-D Navier-Stokes Flow," Physica D 95 (1996), 81-93.

10. D. Armbruster, S. Wang, and P. Crouch, "Bifurcations and Analysis of Oscillations in Electric Power Systems," Proc. of the 35th Conference on Decision and Control, Kobe, Japan, 1996.

11. E. J. Kostelich, J. A. Yorke, and Z. You, "Plotting stable manifolds: error estimates and noninvertible maps," Physica D 93 (1996), 210 222.

12. "Self organization and chaos in a fluidized bed," with C. S. Daw, C. E. A. Finney, ]M. Vasudevan, N. A. van Goor, K. Nguyen, D. D. Bruns, C. Grebogi, E. Ott, and J. A. Yorke, Phys. Rev. Lett., 75 (1995), 2308-2311.

13. "Efficient switchin s between controlled unstable periodic orbits in higher dimensional chaotic systems," with E. Barreto, C. Grebogi, E. Ott, and J. A. Yorke, Fhys. Rev. E 51 (1995), 4169-4172.

14. Y.-C. Lai, C. Grebogi, and E. J. Kostelich, "Extreme final state sensitivity in asymmetric spatiotemporal chaotic systems," Phys. Lett. A 196 (1994), 206-212. 